\title{
S5ynthesis
}

International Scientific Conference of IT and Business-Related Research

\section{UPOREDNI PRIKAZ IMPLEMENTACIJE KONCEPTA JAVNOG-PRIVATNOG PARTNERSTVA U ODABRANIM ZEMLJAMA CENTRALNE I JUGOISTOČNE EVROPE}

\author{
A COMPARATIVE OVERVIEW OF IMPLEMENTATION OF PUBLIC-PRIVATE PARTNERSHIP \\ CONCEPT IN SELECTED COUNTRIES OF CENTRAL AND SOUTHEAST EUROPE
}

\author{
Zoran Grubišić, Ismail Musabegović, Sandra Kamenković \\ Beogradska bankarska akademija, Zmaj Jovina 12, Beograd, Srbija
}

\begin{abstract}
Apstrakt:
Zemlje koje se često suočavaju sa budžetskim deficitom i nedostatkom sredstava za kapitalne investicije mogu imati najveću korist od implementacije koncepta javno-privatnog partnerstva. Rad analizira prednosti i nedostatke ovakvog načina finansiranja, koje su proistekle iz njegove upotrebe u razvijenim zemljama. Predstavlja se stepen primene ovog koncepta u zemljama centralne i jugoistočne Evrope sa naglaskom na Srbiju. Upoređuju se zakonodavni okviri, kao i uspešnost nekih otpočetih ili okončanih projekata. Osnovni cilj jeste da se pruže smernice za neophodna sistemska rešenja, kao i za mere ekonomske politike na osnovu iskustava zemalja koje uspešno primenjuju ovaj koncept, kao i uočenih nedostataka u praksi zemalja u razvoju.
\end{abstract}

\section{Ključne reči:}

modeli finansiranja, JPP, kapitalne investicije.

\section{Abstract:}

Countries that often face budget deficits, and consequently, the lack of funds for capital investments, may have the greatest benefit from the implementation of the public-private partnership concept. This paper analyses the advantages and disadvantages of this funding method, as a result of its use in developed countries. It also shows the degree to which this concept is implemented in the countries of Central and Southeast Europe with an emphasis on Serbia. Legal frameworks, as well as the performances of some ongoing or previous projects are being compared. The main aim is to provide the guidelines for necessary system solutions and measures of economic policy, based on the experiences of the countries that are successfully implementing this concept, as well as the observed deficiencies in the practice of developing countries.

\section{Key words:}

funding models, public private partnership, capital investments.

\section{UVOD}

Koncept javno privatnog partnerstva (JPP) tokom poslednjih decenija postao je veoma atraktivan način finansiranja izgradnje i održavanja infrastrukture javnog sektora. Zemlje u razvoju i tranziciji i njihove Vlade nalaze se pod stalnim pritiskom unapređenja pružanja javnih usluga, pri čemu raspolažu sa ograničenim sredstvima. U nekim državama, poput Srbije, javne institucije su dodatno bile onemogućene da odgovore potrebama zbog administrativnih i zakonskih ograničenja, pa je učešće privatnog sektora još neophodnije. Tokom perioda recesije, a naročito fiskalnih restrikcija, kada se očekuje smanjenje troškova države, JPP naročito dobijaju na značaju.

JPP se najčešće koristi prilikom finansiranja kapitalnih projekata od javnog značaja poput auto puteva i putnih objekata - tunela, mostova, zatim železničkih pruga, luka, aerodroma, gasovoda, društvene infrastrukture, komunalne infrastrukture. Projektni aranžmani nastali po osnovu ulaganja javnog i privatnog kapitala variraju od isključivog učešća privatnog kapitala uz odobrenje i garancije Vlade, do ulaganja u kome su privatni partneri finansijska potpora državi u sponzorisanju projekata.
PPPs на Балкану - секторска структура

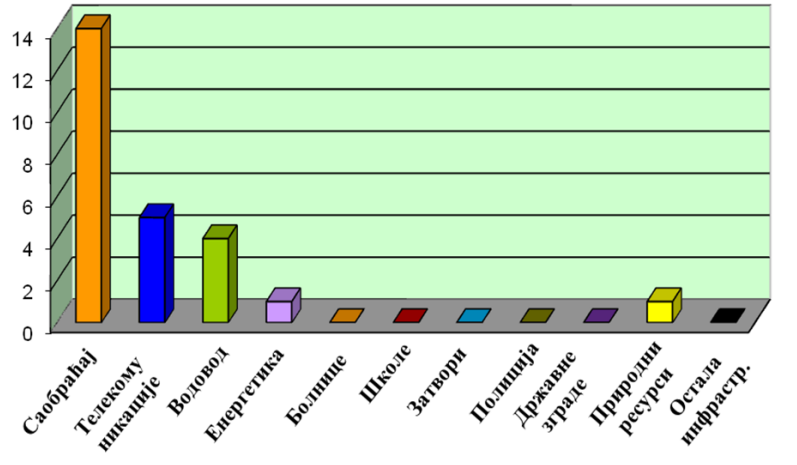

Slika 1: Sektorska struktura PPP na Balkanu Izvor: EIB, World Bank PPI, IFC i komercijalne baze podataka

Prema Zelenom papiru Evropske komisije o JPP (Green Paper on Public-Private Partnerships and Community Law on Public Contracts and Concessions) ovaj koncept uobičajeno karakterišu sledeći elementi: 
- dugi rok trajanja partnerstva, uključujući saradnju između javnog sektora i privatnog sektora u raznim aspektima planiranog projekta;

- izvor finansiranja razvoja projekta ili usluge je privatan sektor, koga često čine aranžmani između mnogo aktera;

- alokacija odgovornosti između partnera privatnog sektora (koji učestvuju u oblikovanju, izgradnji, implementaciji i finansiranju projekta) i partnera javnog sektora (koji se primarno koncentriše na definisanje ciljeva sa aspekta javnih politika, kvaliteta usluga i politike cena)

- alokacija rizika između partnera javnog i privatnog sektora.

\section{Očekivanja investitora JPP}

Svaki od učesnika u ovim projektima ima svoja očekivanja, određene ciljeve i zahteve koje želi da ostvari. Prema Smernicama Evropske komisije učesnici iz privatnog sektora za ulazak u partnerstvo sa javnim sektorom imaju zahteve poput dobijanja razumnog profita, srazmernog uvećanja profitnog potencijala usled visoke izloženosti riziku, jasne pravne i regulatorne strukture, političke podrške i stabilnosti. Ipak, osnovni motiv učešća privatnih subjekata u realizaciji infrastrukturnih projekata je pre svega odgovarajuća finansijska stopa povraćaja na investirani kapital koja bi trebalo da je proporcionalna profitu koju bi mogao da se ostvari ulaganjem u alternativne projekte sličnog rizika.

Sa druge strane, očekivanja javnog sektora su u uticaju na finansiranje projekta u cilju unapređenja njegove realizacije, ubrzanje sprovođenja projekta, unapređenje nivoa usluga, unapređenje pokrivenosti usluga, koristi koje proizilaze iz efikasnosti projekta, kao i olakšanje izvođenja projekata u situacijama kada se koriste spoljna ili donatorska sredstva.

Ukoliko Evropska komisija učestvuje u razvoju i implementaciji infrastrukturnih projekata onda i ona ima svoje zahteve među kojima su najznačajniji postizanje evropskih standarda, maksimiziranje društvene dobiti, transparentnost, razumna kontrola odobrenih sredstava, uticaj na finansiranje projekata.

\section{Pretpostavke za implementaciju JPP}

Brojne su pretpostavke koje određuju mogućnosti i ograničenja JPP. Sredojević (2010) kao najznačajnije ističe:

- Kapacitet javnog sektora - Ukoliko je javni sektor suočen sa deficitom i teretom javnog duga, veoma je verovatno da će koristiti koncept JPP, dok zemlje koje imaju velike izvore eksternih prihoda i meka budžetska ograničenja nisu snažno motivisane za primenu ovog koncepta

- Političko okruženje - Ekonomska politika Vlade koja favorizuje tržišnu ekonomiju je pogodno tle za JPP, te je koncept JPP više zastupljen u zemljama koje imaju političku stabilnost i odgovornu Vladu

- Tržišni uslovi i makroekonomska stabilnost - Koncept JPP je više zastupljen na tržištima sa velikom tražnjom i visokom kupovnom moći, u zemljama sa kredibilnim, predvidivim i stabilnim makroekonomskim uslovima, kao i u zemljama sa niskom stopom inflacije i stabilnim deviznim kursom

- Kvalitet institucionalnog okvira i pravni sistem - Zemlje sa nedovoljno jakim institucijama i administracijom neadekvatnog kvaliteta imaju visok rizik zemlje i posledično loše pretpostavke za implementaciju JPP, dok su JPP veoma uspešna u zemljama koje imaju efikasan pravni sistem koji štiti prava investitora na transparentan način kao i jake i efektivne pravne institucije.

\section{KARAKTERISTIKE JPP TRŽIŠTA JUGOISTOČNE EVROPE}

\section{Bugarska}

U Bugarskoj postoje dva zakona koja regulišu dodeljivanje koncesija, Zakon o koncesijama i Zakon o imovini lokalne samouprave, kao i više podzakonskih akata koji detaljnije regulišu ovu oblast. Usled puno akata koji regulišu ovu oblast može se reći da je opšti okvir za procedure veoma kompleksan, te zahteva efikasnost u koordinaciji institucija javnog sektora i njihov kapacitet da implementiraju odredbe. Bugarska ima JPP jedinicu na nacionalnom nivou, koja je nadležna za savetodavne usluge za potencijalne projekte. Praćenje projekata vrši Vlada, ali na ad hoc osnovi. Održavaju se javne konsultacije o JPP projektima, ali prema izveštajima ESTAT-a većina ispitanih kompanija smatra da su procedure u vezi sa JPP konsultacijama u veoma malom procentu transparentne i objektivne.

Proces privatizacije u Bugarskoj počeo je još 1997. godine. Najčešći oblik saradnje su koncesije. Veoma značajni JPP projekti su Marica Istok 1 i Marica Istok 2 između nacionalne elektro kompanije i inostrane kompanije za pružanje javnih usluga. Dodeljene su i koncesije za rekonstrukcije aerodroma Burgas i Varna, autoput Trakija, koncesije za luke na Dunavu i Crnom moru

Kao primer dobre prakse JPP u Bugarskoj može se navesti Projekat vodovoda u Sofiji (Sofia Water and Wastewater Concession Project). Ovo je bio prvi projekat takve vrste u zemljama Centralne i Istočne Evrope. Projekat je baziran na francuskom modelu koncesija. Glavna karakteristika samog vodovodnog sistema i javnog preduzeća bio je nedostatak investicija, zastarela infrastruktura, preveliki broj zaposlenih, nizak stepen operativne efikasnosti, nepovoljna struktura kapitala, kao i veliki procenat nenaplaćenih prihoda. Finansijski projekat je koncipiran tako da donosi najmanje 150 miliona dolara kapitalnih investicija tokom 15 godina. Projektom rukovodi lokalna samouprava Sofije i cilj je da se mobiliše ekspertiza i kapital privatnog sektora u cilju isporuke značajno kvalitetnijih vodovodnih usluga $i$ ispunjenja evropskih standarda i zahteva potrošača. Projekat je podržan od strane EBRD-a.

Struktura koncesionog aranžmana bazirana je na projektnoj kompaniji u kojoj većinsko učešće (75\%) u vlasništvu i kontrolnom upravljanju ima operater privatnog sektora, kompanija International Water Ltd. Lokalna kompanija kroz javnu kompaniju za vodovod "Vodosnabdevanje i kanalizacija" zadržala je manjinsko učešće u vlasništvu i upravljanju. EBRD, kao senior kreditor Sofijske vode a.d., imala je glavnu ulogu u realizaciji transakcije. Finansiranje kapitalnih investicija, neophodnih tokom prvih pet godina ove koncesije, obezbeđeno je olakšicom senior duga koji je odobrila EBRD na 15 godina, kao i dodatnim učešćem u vlasništvu u kompaniji International Water Ltd. Uspešnom zatvaranju finansijske konstrukcije u relativno kratkom vremenskom okviru doprineli su jasno postavljeni ciljevi, javno i potpuno obavezivanje lokalne samouprave u odnosu na projekat, dobra struktura aranžmana, odgovarajući zakonski okvir, balansirana podela rizika u ugovoru, profitabilnost projekta, transparentnost javnih nabavki, konkurencija između učesnika na tenderu, kao i struktuirani i fazni pregovori.

\section{Mađarska}

Pre pristupanja EU 2004. godine, u Mađarskoj praktično nije postojao zakonski okvir koji bi eksplicitino regulisao oblast JPP. Nakon pristupanja EU, JPP su smatrana pogodnim načinom da se izbegnu ograničenja EU koja se tiču javnog duga 
(koji mora da se drži u okviru 60\% BDP-a) i fiskalnog deficita (maksimim 3\% BDP-a).

JPP i dalje ne postoji kao posebna zakonska kategorija u Mađarskoj. Transakcije u okviru JPP uključuju pravna lica koja su definisana nekim drugim zakonima - Zakonom o konkurenciji, o javnim nabavkama i o koncesijama. Iako u Mađarskoj ne postoji poseban zakon o JPP, a u zakonima o koncesijama javnim nabavkama JPP se uopšte i ne pominje, ova oblast je ipak uređena, i to iz tri perspektive:

- Prvo, sled postupaka koje moraju sprovesti predlagači projekata, kao što su ministarstva i centralni organi vlasti, definisani su vladinim uredbama i odlukama, ali ne i zakonom.

- Drugo, tim istim uredbama i odlukama zahteva se da projekti JPP koje predlaže centralna vlast budu u skladu s razvojnim prioritetima države koje predlaže Državna agencija za razvoj, a odobrava kabinet dva puta godišnje.

- Treće, budući da se svi projekti JPP koji su regulisani ovim uredbama i odlukama finansiraju iz državnog budžeta (a ne iz opštinskih budžeta), godišnji zakon o budžetu, kao i zakon o budžetskom sistemu utvrđuju postupak koji se mora poštovati kada država preuzima novu obavezu.

Primer uspešnog JPP je Program Sport XXI, koji je zamišljen kako bi se delimično subvencionisali sportski objekti u opštinama izdvajanjem iz budžeta i uključivanjem Komisije za JPP. Po prvobitnom planu trebalo je da bude uključeno 18 glavnih gradova županija, da bi konačno samo grad Vesprem izgradio svoju sportsku višenamensku arenu. U većini slučajeva tokom postupaka javne nabavke, nuđene su cene koje su bile za $50-60 \%$ više od cena planiranih tenderskom dokumentacijom, što upućuje na činjenicu da je privatni sektor uočio veliki rizik, koji je pokušavao da prebaci na javni sektor putem viših cena. Na prvom tenderu tokom 2005. godine pojavila su se četiri ponuđača koja su dala svoje ponude za projekat JPP u trajanju od 15 godina i vrednosti od oko 60 miliona evra. Pošto je po tenderskoj dokumentaciji, predviđen trošak iznosio 35 miliona evra, tender je poništen. Nakon toga, raspisan je novi tender 2006. godine i to mesec dana pre lokalnih izbora koji su doneli kompletnu smenu vlasti. Na tender su se javila četiri ponuđača, s tim da su tri ponude morale da se odbace iz formalnih razloga, dok je četvrta ponuda po finansijskim uslovima bila blizu predviđenih troškova tendera koji su predviđali troškove izgradnje od oko 18 miliona evra i operativne troškove od oko 18 miliona evra za period od 15 godina. Jedini validni ponuđač je zatim ponudu podigao na oko 50 miliona evra, pa grad sa njim nije sklopio ugovor. U međuvremenu izgradnja je odpočeta, a kako nije sklopljen ugovor ni sa jednim ponuđačem, kompanija Vesprem komunalne usluge, u stoprocentnom vlasništvu grada, uzela je kredit od komercijalne banke za troškove izgradnje u iznosu od 18 miliona evra. Međutim, uvećanje upisanog kapitala kompanije za komunalne usluge u iznosu od oko 2 miliona godišnje u periodu dok se kredit ne otplati je bilo kreativno rešenje opštinske vlasti kako ovaj dug ne bi ulazio u gradski budžet i kako ne bi ulazio u limit zaduživanja grada.

Pouka koja se može izvući iz primera sportske arene u Vespremu je pre svega kontinuitet na strani relevantnih opštinskih vlasti, kao i sporazum o prihvatljivom nivou investicije i krajnjem cilju koji treba da se ostvari. U kontekstu JPP, pouka je da je neophodno striktno propisati određene standarde za evaluaciju, rangiranje i odobravanje projekata JPP.

\section{Slovenija}

U Sloveniji je pitanje JPP regulisano, pored Zakona o javno-zasebnom partnerstvu, i drugim propisima koji regulišu ovu oblast: Zakonom o javnim nabavkama, Zakonom o radu javnih službi, Zakonom o finansiranju i drugim podzakonskim aktima. Zakon o javno-zasebnom partnerstvu (JZZP) uređuje svrhu i principe privatnih investicija u javne projekte, odnosno javno finansiranje privatnih projekata koji su u javnom interesu. Namera je da se podstaknu JPP i institucije odgovorne za promociju i razvoj. Zakon definiše uslove formiranja i postupke sprovođenja javnog i privatnog partnerstva, posebno koncesija, ugovore, usluge i finansiranje JPP, kontrolu JPP, kao i reformu javnih preduzeća. Ovaj Zakon uvažava Direktive 2004/18/EC Evropskog parlamenta i Saveta iz 2004. godine u vezi koordinacije javnih nabavki dobara i usluga, smernice Evropske Komisije iz 2005. godine, kao i aneks Direktive 2004/18/EC Evropskog parlamenta i Saveta o javnim nabavkama.

Svrha Zakona je da se zakonskom regulativom olakša investiranje i promovišu privatne investicije u izgradnju i održavanje objekata i upravljanje JPP i drugim projektima od javnog interesa. Zakonom se promoviše javno i privatno partnerstvo kroz ekonomičan način i efikasno sprovođenje finansijskih i drugih aktivnosti, na način i pod uslovima koji važe za javni servis. Navode se i druge aktivnosti, čija realizacija je u javnom interesu i odnosi se na racionalnu upotrebu, upravljanje ili eksploataciju prirodnih resursa, izgrađena javna dobra ili druge stvari u javnom vlasništvu. Sa druge strane, definišu se privatne investicije ili drugi privatni i javni resursi koji su neophodni za izgradnju objekata koji su delimično ili u potpunosti u javnom interesu, kao i aktivnosti čija je realizacija u javnom interesu. Dakle, da bi se postigli ciljevi, JPP sprovodi se u oblasti finansija, projektovanja, izgradnje, nadzora, organizacije i upravljanja, održavanja i sprovođenja drugih aktivnosti iz JPP. U delu koji se odnosi na implementaciju Zakona, navodi se da je svrha zakona da obezbedi transparentnost, konkurentnost, spreči diskriminaciju i nepravilnosti kod zaključivanja i primene različitih oblika JPP, a sve u cilju zaštite javnog interesa u ugovornom odnosu.

JPP može biti realizovano kao ugovorno partnerstvo ili partnerstvo u formi odnosa kapitala (institucionalni kapital). Ugovorna partnerstva mogu biti u obliku:

1. koncesionih odnosa tj. bilateralni pravni odnos između države i lokalnih zajednica ili drugih javnih entiteta kao koncedenta i koncesionara, kojim se davaocu koncesije daje pravo na obavljanje javne službe ili druge delatnosti u javnom interesu, koji mogu uključivati izgradnju objekata koji su delimično ili u potpunosti u javnom interesu ili

2. javne nabavke, tj. odnos između kupca i dobavljača, sa ciljem nabavke dobara, izvođenja radova ili usluga.

Kako bi se bolje objasnili procesi koji vode formiranju JPP aranžmana - metode, procedure, ali i potencijalne prepreke, treba sagledati primer pozitivne prakse o ostvarenim rezultatima i koristima za lokalnu zajednicu u Sloveniji. Predstavićemo dva primera JPP - Stadion Stožice i Tehnološki Park Ljubljana.

Vrednost JPP projekta Stadion i višenamenska hala Stožice je 220 miliona eura. Njegova izgradnja je rezultat JPP između Grada Ljubljane i komapanije Grep development koja je osnovana sa ciljem da implementira projekat Gradis skupine i Energoplana. Naknadno se uključio još jedan strani partner, Supernova. U okviru navedenog iznosa privatni partner je izgradio sledeće objekte: stadion, sportsku halu i tržni centar - šoping mol, ali i parking za potrebe sportskih objekata i tržnog centra, skejt park, malo igralište za rekreativne svrhe, džoging stazu i dr. Javni partner je dobio sve sportske objekte i njihova vrednost iznosi oko 80 miliona eura. Privatni partner je dobio tržni centar, uključujući i vlasništvo nad zemljištem koje pokriva tržni centar.

Tehnološki park Ljubljana predstavlja centar za pripremu inovativnih ideja i novih progresivnih projekata, koji će kroz implementaciju od strane preduzeća podstaći ekonomski razvoj 
i zapošljavanje, posebno mladih stručnjaka iz različitih oblasti na području Ljubljane i cele Slovenije, kao i pružiti pomoć firmama koje žele da se brže razvijaju. Aktivnost Tehnološkog parka se može podeliti u tri oblasti:

1. fizička infrastruktura, kao što je izgradnja softvera,

2. pružanje standardnih usluga - računovodstveni poslovi, pravni poslovi, neposredno obavljanje poslova za potrebe firmi ili pružanje kvalitetnih saveta, i

3. specifične usluge - pružanje pomoći kod osnivanja firmi sa domaćim, mešovitim ili stranim kapitalom, ideje o oblasti kojima će se firma baviti, edukacija kadrova za uspešan rad i poslovanje, povezivanje partnera u cilju zaključivanja poslovnih ugovora, obezbeđivanje jeftinih usluga (najam prostorija), uslovi za finansiranje projekata i sl.

\section{Srbija}

Oblast JPP u Srbiji je regulisana Zakonom o javno-privatnom partnerstvu i koncesijama kojim je u pravni sistem Republike Srbije uveden pojam javno-privatno partnerstvo čime je omogućeno Vladi, autonomnoj pokrajini i jedinici lokalne samouprave da donese odluku o pokretanju postupka za realizaciju projekta javno-privatnog partnerstva. JPP predstavlja dugoročnu saradnju javnog i privatnog partnera radi obezbeđivanja finansiranja, izgradnje, rekonstrukcije, upravljanja ili održavanja infrastrukturnih i drugih objekata od javnog značaja i pružanja usluga od javnog značaja, a može biti institucionalno ili ugovorno, kao i koncesija kao poseban oblik ugovornog javno-privatnog partnerstva. Projekti JPP tebalo bi da budu ekonomski efikasni i socijalno odgovorni. Koncept JPP koji se prvi put pojavljuje u našem pravnom sistemu, predstavlja bolju opciju od dosadašnjih modela finansiranja investicija poput zaduživanja u inostranstvu, korišćenja sredstava „Nacionalnog investicionog plana”, finansiranja od strane javnih preduzeća ili direktno iz budžeta, koji su se pokazali kao nedovoljno efikasni. Takođe, radi pružanja stručne pomoći pri realizaciji projekata JPP i koncesija, kao međuresorno javno telo operativno nezavisno u svom radu, Vlada je obrazovala Komisiju za JPP.

$\mathrm{Na}$ lokalnom nivou, investicije privatnog sektora $\mathrm{u}$ infrastrukturu vršene su u skladu sa Zakonom o komunalnim delatnostima iz 1997. godine, koji je davao mogućnost da se obavljanje komunalne delatnosti poveri drugom preduzeću. Ovaj Zakon predstavlja temelj većine javno - privatnih partnerstava koja funkcionišu na nivou lokalne samouprave u Srbiji, a najviše ih je u sektoru održavanja čistoće i upravljanju otpadom. To su, na primer, A.S.A. Kikinda d.o.o, kao JPP strane kompanije A.S.A. u vlasništvu španskih investitora i Skupštine opštine Kikinda, A.S.A. Vrbak, odnosno A.S.A. Eko d.o.o, kao JPP iste strane firme sa grupom opština iz Šumadije (institucionalni oblik JPP) i TROJON\&FICHER EKO - mešovita srpskonemačka kompanija, kojoj su opštine Žagubica, Žabari, Malo Crniće, MZ Rabrovo (Kučevo) i Smederevska Palanka poverile obavljanje komunalne delatnosti sakupljanja i odlaganja čvrstog otpada. Do sada je priliv privatnog kapitala zabeležen najviše u sektorima koji zahtevaju manje investicije, poput usluga parkiranja ili upravljanja čvrstim otpadom, jer su finansijska ulaganja najmanja (do 40 miliona evra), a najmanji je i rizik. Najveće investicije zahtevaju sektori vode i kanalizacije, naročito u Beogradu, gde je procenjeno da je potrebno obezbediti investiciju od čak 987 miliona evra.

Što se tiče trenutnog svetskog trenda JPP, najviše ovakvih projekata je u oblasti saobraćaja i puteva, izgradnje mostova, sportskih hala i telekomunikacija. Od juna 2012. godine do septembra 2014. godine Komisija za JPP je donela pozitivno mišljenje o dvadeset Predloga projekata JPP sa ili bez elemenata koncesije. Među najznačajnijim su:

1. Predlog projekta JPP od strane JKP Informatika Novi Sad, kojim se predlaže realizacija projekta izgradnje i proširenja postojeće optičke telekomunikacione mreže otvorenog tipa po principu FTTH

2. Predlog projekta JPP za izgradnju luke i drumskog terminala podnetog od strane Javnog preduzeća za građevinsko zemljište, izgradnju i puteve „Direkcija za izgradnju Apatin“, na teritoriji opštine Apatin

3. Predlog projekta JPP podnetog od strane JKP Gradska toplana Zrenjanin, kojim se predlaže proizvodnja toplotne i električne energije iz biogasa

4. Predlog koncesionog akta sa Analizom finansijsko-ekonomskih efekata davanja koncesije na auto-put E-763, Beograd-Požega.

Možda najpoznatiji projekat JPP za sada je sproveden u oblasti javnog prevoza u Beogradu (Sistem za naplatu karata i upravljanje vozilima u javnom prevozu u Beogradu - popularni Bus Plus). Iako se formalno ne radi o projektu JPP, s obzirom da je zasnovan na ugovoru zaključenom pre stupanja na snagu Zakona o javno-privatnom partnerstvu, u ovom projektu suštinski je ostvaren partnerski odnos karakterističan za JPP. Naime, Grad Beograd, Direkcija za javni prevoz, zaključila je sa najpovoljnijim ponuđačem na tenderu ugovor o uspostavljanju i obezbeđenju funkcionisanja sistema za naplatu karata i upravljanje vozilima u javnom prevozu, prema kome privatni partner ima obavezu da obezbedi predmetni sistem, obezbedi distribuciju karata i kontrolu njihovog korišćenja u vozilima javnog prevoza, a kao naknadu za to ima pravo na procentualno učešće u prihodu od prodatih karata.

\section{Izazovi u implementaciji JPP u Srbiji}

Primena i mogućnosti finansiranja JPP u Srbiji susreću se sa brojnim izazovima i ograničenjima. Jedan od izazova je globalna finansijska kriza koja naglašava probleme koji su inače prisutni u zemljama u razvoju poput Srbije. Dakle, investitori su po prirodi veoma oprezni, a u slučaju kada su rizici poslovanja veliki, kada postoje institucionalna i regulatorna ograničenja, kada je iskustvo u primeni JPP minimalno, a kvalitet projekata veoma upitan, investitori su demotivisani da ulaze u ovakve projekte. Okolnosti upućuju na zaključak da će u početnoj fazi razvoja koncepta JPP u Srbiji, dominantno na strani investitora učestvovati finansijske organizacije, poput Evropske banke za obnovu i razvoj (EBRD) i Evropske investicione banke (EIB). Ono što je praksa pokazala kao nedostatak ovakvih investitora je činjenica da sam postupak traje značajno duže, s obzirom da postoje specifični ekološki, socijalni ili zahtevi u pogledu javnih nabavki. Takođe, s obzirom da je Zakon donet u vreme krize, kada se ugovori po prirodi sporije zaključuju, izvesno je da će u početnoj fazi trajanje postupka zaključenja ugovora o JPP biti duže, što bi dodatno moglo da utiče na nezainteresovanost ulagača da uđu na srpsko tržište.

Iskustvo Bugarske, Mađarske i Slovenije može biti poučno za Srbiju. Karakteristike svih uspešnih JPP su jasno postavljeni ciljevi, javno i potpuno obavezivanja lokalne samouprave projektu, dobra struktura aranžmana, balansirana podela rizika, transparentnost javnih nabavki, konkurencija na tenderu, struktiurani i fazni pregovori, striktno propisani standardi za evaluaciju, rangiranje i odobravanje projekata.

Mera podrške države koja se u međunarodnom iskustvu pokazala kao podsticajna za razvoj JPP je pre svega finansijska podrška, kroz davanje garancija (republike i lokalnih samoupra- 
va) kako bi se omogućilo povoljnije finansiranje projekata. Međutim, sa ovom merom bi trebalo da se bude oprezan imajući u vidu da izveštaji Fiskalnog saveta ukazuju na veoma veliki iznos državnih garancija, pre svega javnim preduzećima.

\section{REZIME}

U radu je predstavljen koncept javno-privatnog partnerstva, očekivanja investitora, pretpostavke za implementaciju na osnovu iskustva razvijenih zemalja. S obzirom da su zemlje jugoistočne Evrope, a među njima i Srbija, često suočene sa budžetskim deficitima i nedostatkom sredstava za kapitalne investicije, one bi mogle imati najveću korist od implementacije koncepta javno-privatnog partnerstva. Predstavljena su iskustva Bugarske, Mađarske, Slovenije i Srbije, kao zemalja jugoistočne Evrope koje su u različitim statusima u pogledu pristupa Evropskoj uniji. S obzirom da je cilj rada dati smernice za Srbiju, u smislu neophodnih rešenja i mera ekonomske politike, dat je pregled izazova na koje se može naići tokom implementacije, kao i mera države koja bi tu implementaciju mogla da podrži. Do septembra 2014. godine Komisija za javno-privatna partnerstva je dala pozitivno mišljenje o 20 predloga projekata javno-privatnog partnerstva u Srbiji, ali deluje da projekti sporo napreduju, te je očigledno neophodan dodatan podsticaj države. Iz iskustva zemalja u okruženju pokazalo se da je za dalji razvoj koncepta javno-privatnog partnerstva kritičan uspeh prvih projekata, jer bi neodmereno korišćenje mera države moglo da stvori veliko budžetsko opterećenje sa jedne strane, a sa druge neuspeh početnih projekata bi značajno usporilo dalji razvoj projekata javnoprivatnog partnerstva u datoj zemlji.

\section{LITERATURA}

Benković, S., \& Barjaktarović-Rakočević, S. (2011). Modeli javnoprivatnog partnerstva u finansiranju infrastrukturnih projekata, SPIN ,11, VIII Skup Privrednika i naučnika: Operacioni menadžment u funkciji održivog ekonomskog rasta i razvoja Srbije 2011-2020. Beograd: FON.

Damjanović, D., Pavlović-Križanić, T., \& Peteri, G. (2010). Partnerstvo javnog i privatnog sektora - Dobra i loša iskustva u odabranim zemljama u tranziciji, Beograd: PALGO centar.

EUR-Lex. (2004). Green paper on Public private partnerships and community law on public contracts and concessions. Preuzeto sa http://eur-lex.europa.eu/legal-content/EN/TX $\mathrm{T} /$ ?qid=1433509264024\&uri=CELEX:52004DC0327

European Commission. (2003). Guidelines for Successful Public - Private Partnerships. Preuzeto sa http://ec.europa.eu/regional_policy/sources/docgener/guides/ppp_en.pdf

Nenezić, D., \& Radulović, B. (2012). Analiza mogućnosti i modaliteta finansiranja i mera finansijske podrške javno-privatnog partnerstva u Srbiji, Kvartalni monitor, 30, jul-septembar 2012. Beograd: FREN.

Prijić, M., Ristić, K., \& Šteković, M. (2011). Javno-privatno partnerstvo i koncesije, Z-26/10. Beograd: Biblioteka Narodne Skupštine.

Službeni glasnik Republike Srbije. (1998). Zakon o komunalnim delatnostima. Službeni glasnik RS, br. 16/97 i 42/98.

Službeni glasnik Republike Srbije. (2011). Zakon o javno-privatnom partnerstvu i koncesijama. Službeni glasnik RS, br. $88 / 2011$.

Sredojević S. (2010). Javno-privatno partnerstvo. Beograd: Arhipelag, Institut ekonomskih nauka.

Uradni list RS. (2006). Zakon o javno-zasebnem partnerstvu. Uradni list RS, št.127/06. 